\title{
Translocation Protocol for the Ord's Kangaroo Rat (Dipodmys ordii)
}

\section{Fish \& Wildlife \\ Division}

\section{SPECIES AT RISK}

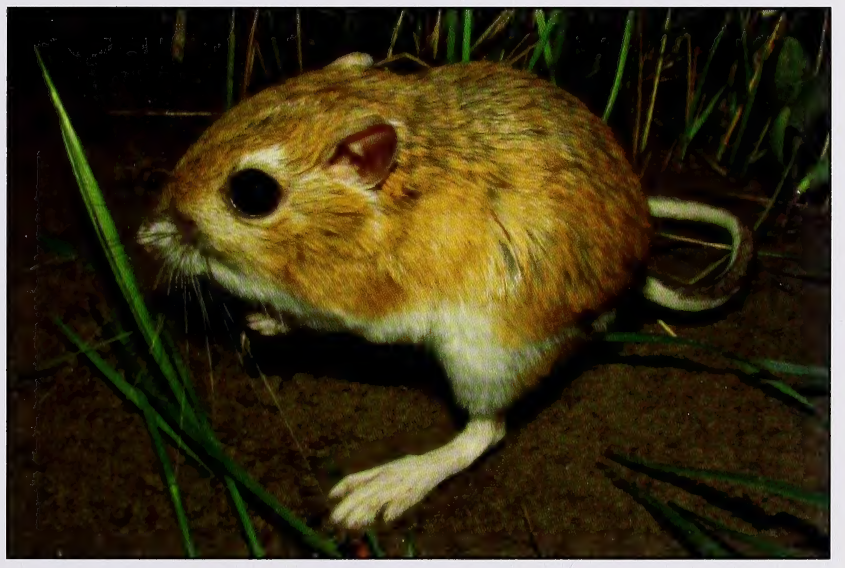


Digitized by the Internet Archive in 2016 


\section{Translocation Protocol for the Ord's Kangaroo Rat (Dipodmys ordii)}

Darren J. Bender, Randy Dzenkiw, and David L. Gummer

Alberta Species at Risk Report No. 131

March 2010

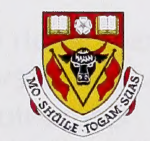

UNIVERSITY OF

CALGARY

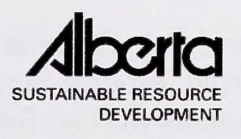

Fish \& Wildlife 
Publication No:: $1 / 434$

ISBN: 978-0-7785-9028-6 (Printed Edition)

ISBN: 978-0-7785-9029-3 (On-line Edition)

ISSN: 1496-7219 (Printed Edition)

ISSN: 1496-7146 (On-line Edition)

Cover Photograph: Randy Dzenkiw

For copies of this report, contact:

Information Centre - Publications

Alberta Environment/Alberta Sustainable Resource Development

Fish and Wildlife Division

Main Floor, Great West Life Building

9920 - 108 Street

Edmonton, Alberta, Canada T5K 2M4

Telephone: (780) 422-2079

OR

Visit our web site at:

http://srd.alberta.ca/BioDiversityStewardship/SpeciesAtRisk/Default.aspx and click on "Project Reports"

This publication may be cited as:

Bender, D.J., R. Dzenkiw, and D.L. Gummer. 2010. Translocation Protocol for the Ord's Kangaroo Rat (Dipodmys ordii). Alberta Sustainable Resource Development, Fish and Wildlife Division. Alberta Species at Risk Report No. 131. Edmonton, AB. 18 pp. 


\section{TABLE OF CONTENTS}

EXECUTIVE SUMMARY .................................................................................

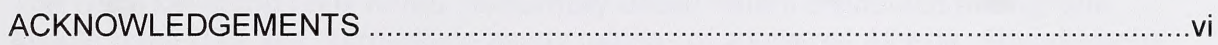

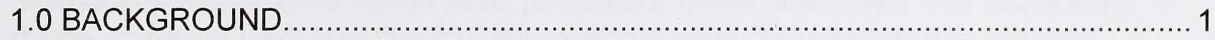

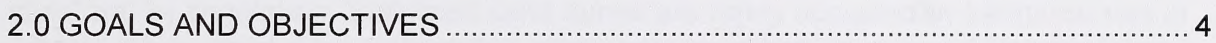

3.0 DESIGN CONSIDERATIONS FOR PLANNING TRANSLOCATIONS .................. 5

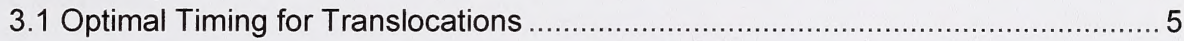

3.2 Consideration of Age and Sex when Collecting Animals for Translocation............ 6

3.3 Identify Source Locations ....................................................................... 7

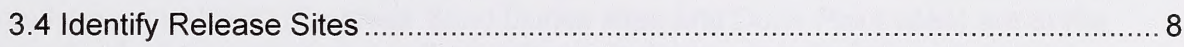

4.0 DESIGN CONSIDERATIONS FOR HANDLING AND RELEASE ...................... 10

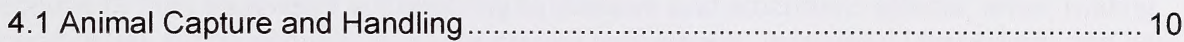

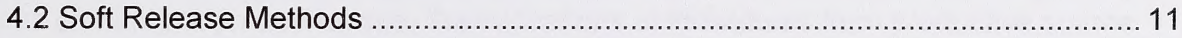

5.0 POST-RELEASE INVESTIGATIONS AND MONITORING ............................ 13

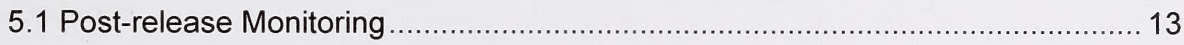

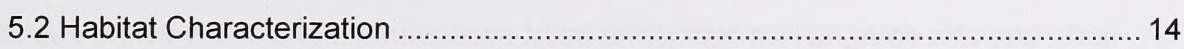

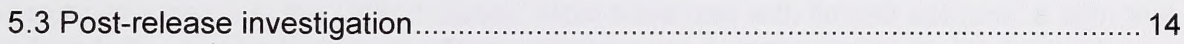

6.0 CONCLUSIONS AND RESEARCH RECOMMENDATIONS ............................ 15

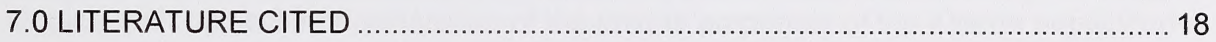




\section{LIST OF FIGURES}

Figure 1. Range of extent for the Ord's kangaroo rat in Alberta based on capture records from 1994 - 2009.

Figure 2. Distribution of natural and principal anthropogenic (i.e. road) habitats occupied by Ord's kangaroo rats in Alberta. 


\section{EXECUTIVE SUMMARY}

The Ord's kangaroo rat is a rare, nocturnally-active rodent distributed through the Middle Sand Hills and surrounding sandy regions of southeast Alberta. Abundance is highest in areas of loose sandy soils, particularly those associated with active sand dunes. In recent decades, much of the available sand dune habitat has become stabilized by vegetation. Stabilized sand dunes are rarely occupied by kangaroo rats in Alberta. Thus, sand dune stabilization represents rapid habitat loss and fragmentation for the species and has led to a number of disjunct and isolated sub-populations within the province.

Recent research has identified the location of habitats for the Ord's kangaroo rat in Alberta, including a number of isolated patches of natural habitat. Population projections based on computer simulation models have indicated that the two most isolated subpopulations in Alberta (Empress Sand Dunes sites and Dune Point sites) are at the highest risk of extirpation due to their extreme isolation, despite their high habitat quality. Other small, isolated sub-populations may also be susceptible to extirpation because of their increased vulnerability to disease and stochastic effects, fewer mating opportunities which can lead to lower animal recruitment, increased inbreeding, and low rates of immigration and rescue. Translocations of individuals from productive source sites in the population to small and isolated or declining sites has been identified as a management tool to mitigate local extirpations and strengthen regional population persistence.

Various translocation experiments have been performed on kangaroo rats and other heteromyid rodents in the United States. Most have met with limited success, a sign that the feasibility of using kangaroo rat translocations as a conservation tool is not well understood. This report provides recommended methods for translocating Ord's kangaroo rats in Alberta based on the successes and limitations observed in previous studies, with particular consideration of the unique properties of the Alberta population (e.g., bot fly parasitism).

This report also describes knowledge gaps and recommended research that should be undertaken to determine whether Ord's kangaroo rat translocations can be used in Alberta to mitigate population decline and local extirpation of isolated habitats. Although the feasibility of using translocations as a management tool is not well understood, it is hoped that future research in Alberta can identify best practices for translocations to provide a valuable conservation tool for managers who wish to ensure the future persistence of this endangered species. 


\section{ACKNOWLEDGEMENTS}

This work was supported by funding and in-kind support from: Alberta Sustainable Resource Development (ASRD), Canadian Forces Base Suffield, and the University of Calgary. Gavin Berg (ASRD) provided editorial assistance. The authors wish to thank Drs. Kelley Kissner and Arlen Todd for their advice and improvements to this report. 


\subsection{BACKGROUND}

The Ord's kangaroo rat (Dipodomys ordii Woodhouse, 1853) is a medium-sized, nocturnally-active rodent in the family Heteromyidae. The species has a limited distribution in Alberta (Figure 1). The core of the Alberta range is the Middle Sand Hills region, and peripheral sub-populations exist in adjacent regions, particularly the Dune Point sand dunes near Bindloss, $A B$ and the Empress dunefield near Empress, $A B$ (Figure 2). Although most of the Middle Sand Hills lies within CFB Suffield, the current range of the species and much of its population exists on provincial lands.

Ord's kangaroo rats require sparsely vegetated, loose sandy soils that facilitate their hopping style of locomotion and burrow establishment (Gummer 1997a, b). The natural habitat of this species in Alberta is generally restricted to actively eroding sand dunes. The species also occupies anthropogenic (i.e. human-created) habitats, such as sandy roads, trails, fireguards or margins of cultivated fields, but these habitats are not considered to be of the same quality as natural habitats (COSEWIC 2006).

Recent research (Bender et al., xxxx, and Heinrichs et al., in review) has mapped the expected locations of all habitats supporting kangaroo rats in Alberta. Heinrichs et al. (in review) have used a spatially-explicit population viability approach to determine the likelihood of regional and local (i.e. patch-scale) extirpation, and identified that a number of peripheral sub-populations are at significant risk. In particular, two locations, the Dune Point sand dunes near Bindloss, $A B$ and another small complex of dunes near Empress, $A B$ (Figure 2), are at high risk of becoming extirpated over the next 50 to 100 years, despite the observation that they may represent some of the highest quality habitat in Alberta (based on population density and apparent productivity; see Heinrichs et al., in review). Presumably, the recent ( $<100$ year) isolation of these habitats by stabilization of intervening sand hills and conversion of native prairie to cropland has effectively isolated these sub-populations, greatly reducing the likelihood for immigration and recolonization from nearby sub-populations.

Under these conditions, which are likely not to be reversed, isolated sub-populations cannot be supplemented by natural immigration from adjacent areas to rescue them from declines and extirpation. The only opportunity that currently exists for rescue or recolonization of isolated habitats is human intervention by conducting translocations of kangaroo rats.

The Alberta Recovery Plan for the species (Alberta Ord's Kangaroo Rat Recovery Team, 2005) recommended that translocations of individuals should be investigated as a conservation tool to manage the species and prevent its extirpation in Alberta. This report reviews current information about translocating kangaroo rats and other heteromyid rodents. It provides recommended methods for conducting translocation studies and describes research needed to examine the feasibility of using translocations to manage the Alberta regional population. 


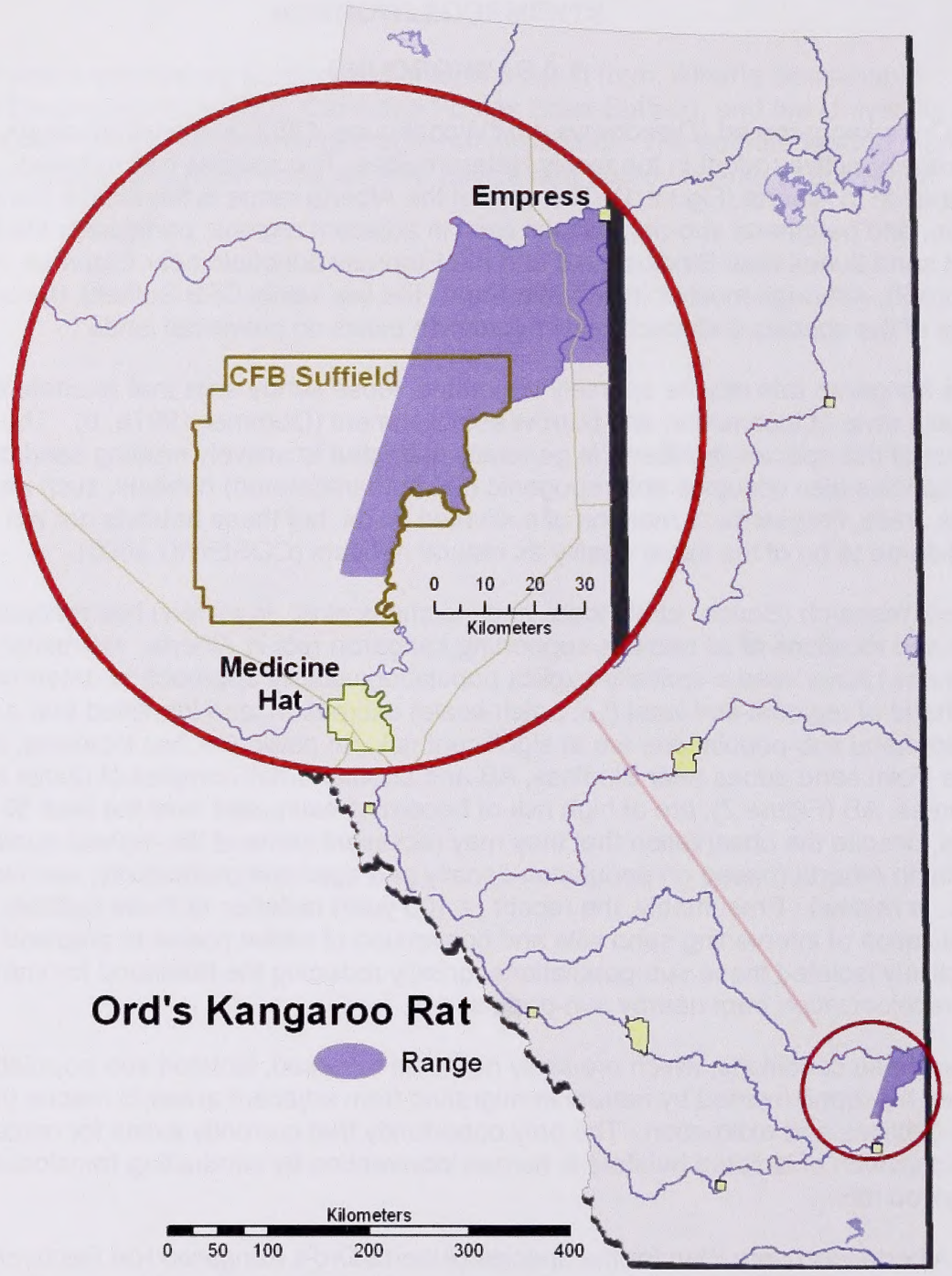

Figure 1. Range of extent for the Ord's kangaroo rat in Alberta based on capture records from 1994 - 2009. 


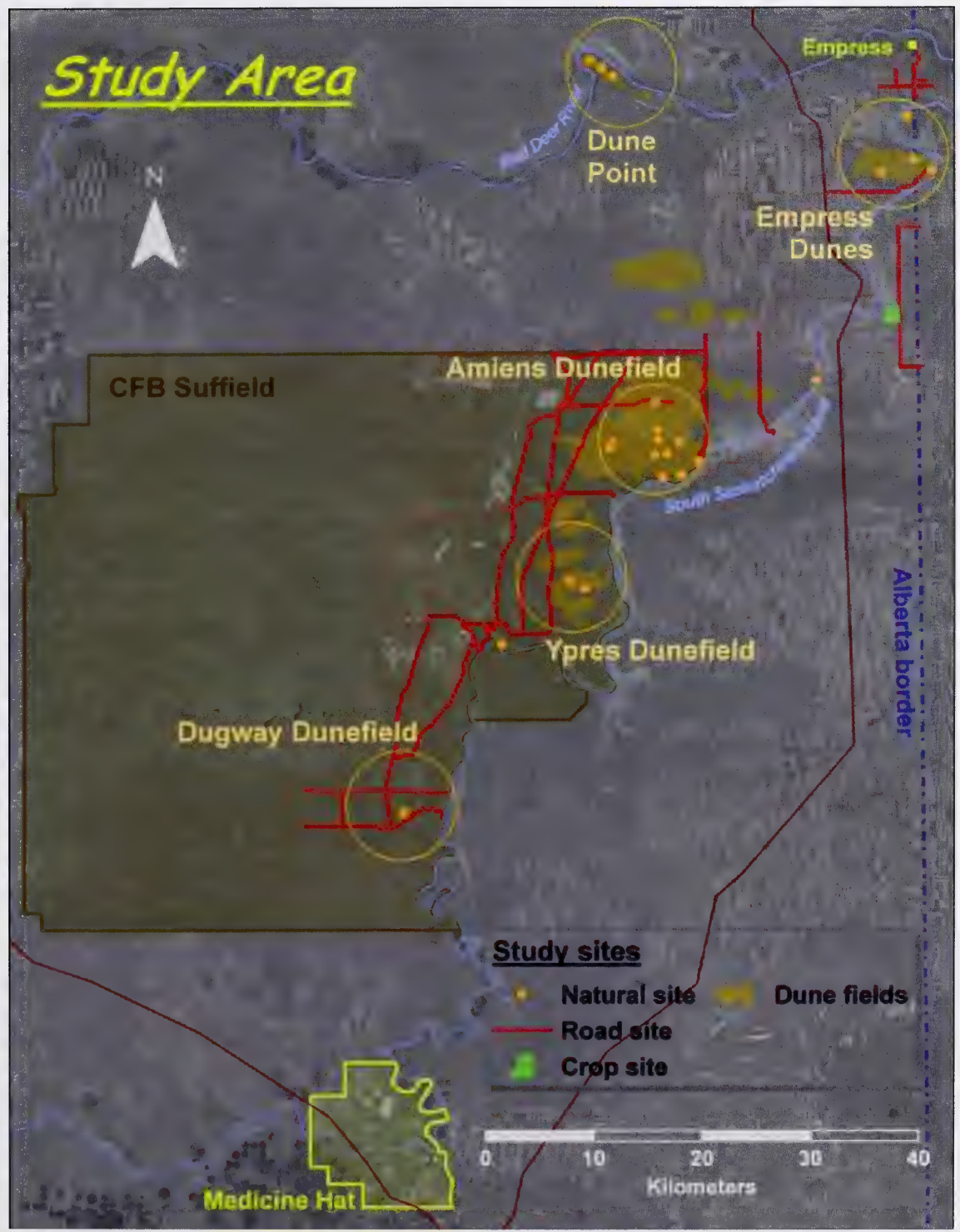

Figure 2. Distribution of natural and principal anthropogenic (i.e. road) habitats occupied by Ord's kangaroo rats in Alberta. 


\subsection{GOALS AND OBJECTIVES}

The ultimate goal of using translocations as a conservation tool is to help ensure a "viable, naturally self-sustaining population of Ord's kangaroo rats in Alberta" (Alberta Ord's Kangaroo Rat Recovery Team 2005). If successful, translocations may provide managers with a tool to augment natural immigration processes, thereby rescuing isolated populations at risk of local extirpation, or by recolonizing areas that have become locally extirpated, ultimately improving the size and stability of the regional population in Alberta.

A large number of considerations are required to conduct successful translocations that simultaneously: minimize injury or death of animals, maximize the likelihood of establishment and survival at the release site, and promote the future growth of the entire regional population.

We suggest that such considerations can be best addressed by adopting the following objectives for successful kangaroo rat translocations:

1. Determine the optimal timing for conducting translocations.

2. Define how age, sex, and reproductive class of kangaroo rats relate to potential for successful translocation.

3. Identify possible source locations for translocated individuals, with the intent of moving kangaroo rats to areas of higher habitat quality (i.e. greater access to resources) than at their collection site.

4. Identify release sites that will increase area of occupancy and population connectivity for the regional population. Area of occupancy can be increased by translocating animals to unoccupied sites (e.g., recently extirpated habitat patches of suitable quality, stabilized or semi-stable sand dunes that have undergone habitat restoration treatments, or sand dunes that have recently become de-stabilized by wildfire). Connectivity can be improved by translocating animals to sites identified as spatially influential habitats (e.g., stepping stones) in computer simulation models (e.g., Heinrichs et al., in review).

5. Develop a strategy that will mitigate stress, injury and death to kangaroo rats during and immediately following the translocation process.

6. Improve chances for site establishment by using soft release techniques.

7. Conduct post-release monitoring at source and release sites to evaluate effects of the translocations.

8. Determine relations (if any exist) between habitat variables at source or release translocation sites and survival of translocated individuals. Apparent positive and negative relations can be used in an adaptive manner to prioritize or eliminate future translocation sites and optimize animal survival.

Each of these objectives is discussed in detail in the following sections. Section 3 discusses design considerations to be made prior to translocations, Section 4 discusses considerations for handling and release techniques in the field, and Section 5 
discusses post-release investigations and monitoring techniques. The report concludes with general conclusions and some recommendations for research to fill the identified gaps in knowledge in Section 6.

\subsection{DESIGN CONSIDERATIONS FOR PLANNING TRANSLOCATIONS}

A number of design considerations must be planned before translocations are conducted, including the optimal timing for conducting translocations, the selection of animals for translocations, and the identification of source and release sites.

\subsection{Optimal Timing for Translocations}

There are three key considerations to determine the optimal time to capture, translocate, and release Ord's kangaroo rats: time of year, time of month/lunar condition, and time of day.

The time of year in which translocations occur may be critically important to their success. Ord's kangaroo rats in Alberta are believed to suffer high over-winter mortality, particularly if cold winters with heavy snow cover prevent animals from foraging for extended periods of time (Gummer 1997, COSEWIC 2006). Although kangaroo rats establish extensive seed caches to conserve metabolic resources during the winter, it is presumed that a leading cause of mortality is starvation, when the food caches are depleted (Gummer 1997, Gummer 2005). Thus, translocations should be conducted early enough each year that animals have ample opportunity through the summer and fall to establish adequate seed caches. Late-summer, fall, or winter translocations are not likely to be successful because animals may not have enough time following release to accumulate a large enough amount of food items prior to winter. Late-spring or early summer translocations (i.e. May to June) are recommended to maximize the time available for foraging and cache-building prior to the subsequent winter.

Another consideration for choosing the time of year in which translocations should be undertaken is the timing of bot fly parasitism. The Ord's kangaroo rat in Alberta is parasitized by the bot fly, Cuterebra polita (Gummer et al. 1997), with evidence to suggest such parasitism can be detrimental to the body condition and health of its host (Robertson 2007). To avoid the risk of spreading bot fly larvae into release sites, kangaroo rat translocation efforts should be attempted before bot fly emergence and egg-laying, which typically occur in late spring and early summer (late-June to early-July).

Ord's kangaroo rats are known to concentrate their above-ground activity (e.g., foraging) during the periods of the month when moonlight is low or absent (Gummer 1997). During periods of the lunar cycle when there are bright moonlit nights, kangaroo rats may be more exposed to visually-orienting predators, such as owls, coyotes, and foxes. Thus, it is recommended that translocations be conducted during the new moon 
period of the lunar cycle each month to facilitate animal capture and reduce exposure of released kangaroo rats to higher predation risk.

Given that kangaroo rats restrict their activity to the night-time period only, effort should be made to capture kangaroo rats as early as possible in the evening and then released as soon as possible, particularly if soft release methods are not used (see Section 4.2 below). This provides the best opportunity for kangaroo rats to use the remaining nighttime period to find shelter. If translocations are conducted in May or especially June, the night-time period is very short so delays in handling, transportation, or release must be minimized. Collection and translocation should be minimized or avoided on nights of inclement weather that may also reduce activity (see Bender et al. 2007)

\subsection{Consideration of Age and Sex when Collecting Animals for Translocation}

Not all animals may be equally suited to successful translocation. More importantly, if the overall goal of translocations is to contribute to the future persistence of the regional population, then the age, sex, and reproductive status of animals to be translocated must be considered. In particular, the value of moving an individual away from a source site to a release location should outweigh the potential costs associated with the translocation (e.g., accidental injury, separation of lactating females from offspring in the nest).

The effects of translocating different age, sex and reproductive categories are considered below:

- It should always be assumed that lactating females have offspring in their nest. Thus, these individuals should not be translocated because offspring would be left behind and almost certainly die.

- Due to their short receptive period, estrous females should not be targeted for translocations because the process may interrupt/limit their breeding and result in missed opportunities for mating.

- Non-reproductive females and adult male kangaroo rats represent good targets for translocations, particularly if a natural sex ratio (approximately 50:50) can be established at release sites.

- Juvenile kangaroo rats (i.e. young of the year) may also represent a desirable group for translocations for numerous reasons. First, they are already more inclined to disperse from the capture locations than local adults with established territories, and a well-planned translocation may help them reach a higher quality site than they might have naturally. Second, translocation movements may limit the exposure of individuals to natural injury or predation that is associated with moving through a potentially hostile matrix while dispersing, which may be especially important for naïve juveniles that have little or no experience with habitats other than those near the nest burrow. Third, the use of juveniles in a translocation program may better emulate natural population dynamics and population age-structure at recolonized sites (assuming that natural dispersal is dominated by juveniles; e.g., see Gliwicz 1991). Fourth, if a portion of the 
juvenile cohort is removed from a highly productive site that is likely to become over-populated (i.e. density exceeds habitat capacity) later in the season, then translocations to unoccupied or under-utilized sites may actually increase the chance of survival for translocated juveniles.

- Williams et al. (1993) reported success moving an equal mix of sexes of giant kangaroo rats $(D$. ingens) in California. To achieve an equal mixing may require a more targeted approach to capturing the animals. For example, examination of past capture records might be used to target kangaroo rats of an appropriate gender if opportunistic captures are yielding a skewed gender ratio (e.g., might happen if males are mate-searching in the spring and are more frequently encountered by surveyors than adult females).

\subsection{Identify Source Locations}

A guiding principle for translocations should be to improve conditions for any relocated individual. Thus, translocated kangaroo rats should be collected at source sites that are low quality sites, such as sandy roads or fireguards, and/or sites known to exhibit high seasonal densities of kangaroo rats where access to resources may be limited and/or there are high levels of seasonal emigration.

Numerous opportunities exist to translocate animals from anthropogenic habitats, such as sandy roads and fireguards, or cultivated fields. However, many of these sites are already at low density, and the removal of individuals may significantly reduce subsequent mating opportunities for remaining animals, reducing the overall productivity of the site immediately following translocation. Thus, translocations from anthropogenic habitats should be targeted at relatively high-density sites. The highest densities of kangaroo rats occupying anthropogenic habitats in Alberta occur along roads and fireguards near the northeast corner of CFB Suffield. This is close in proximity to many desirable release sites, most of which lie in Amiens and Ypres dunefields of the Middle Sand Hills (see Figure 2).

Other opportunities for translocating individuals exist at highly productive natural sites that are observed to produce high densities of juveniles that are likely to emigrate. Population densities peak in early summer at these sites, and the fates of emigrating individuals is not known. Computer simulation models (Heinrichs et al., in revew; Heinrichs, unpublished data) suggest that a small proportion of emigrants reach natural habitat, which is partially confirmed by anecdotal evidence from mark-recapture studies (Bender, Gummer, \& Dzenkiw, unpublished data), but the vast majority are expected to either occupy nearby anthropogenic habitat or perish while emigrating. Thus, the removal of a small portion of the population at a highly productive site early in the season is unlikely to reduce the peak number of individuals at this site later in the season because resources are limiting, particularly if the habitat patch is large and supports a large number of kangaroo rats each year.

Another potential source for Ord's kangaroo rats are those found outside Alberta. The nearest population from a different jurisdiction occurs in Saskatchewan. Most sub- 
populations found there are separated from Alberta kangaroo rats by at least $40 \mathrm{~km}$ of inhospitable habitat (COSEWIC 2006). It is not known if this geographic separation has led to significant genetic differences between the populations. Therefore, genetic studies of both populations would be required before translocation could be considered between the two provinces. The nearest known population of kangaroo rats in the United States is $270 \mathrm{~km}$ to the south and Canadian kangaroo rats appear to have unique life history and physiological characteristics relative to more southern conspecifics (COSEWIC 2006). Thus the likelihood of genetic distinctiveness increases when comparing populations in Alberta with populations of Ord's kangaroo rats in the United States. Translocation attempts are not recommended between these regions.

\subsection{Identify Release Sites}

To ensure that kangaroo rats are translocated to high quality release sites, only sand dune habitats should be considered as candidate release sites for translocations. These sites may be actively eroding sand dunes that are currently under-utilized or not occupied by kangaroo rats or they may be sand dunes that were recently restored or reactivated by wildfire. Research by Teucher (2007) and Robertson (2007) strongly suggests that animals can be expected to have higher survival at natural sites due to decreased risk of predation, parasitism, and winter starvation.

Williams et al. (1993) compared the success of translocations at a natural and anthropogenic (fallow field) release site. While the animals at the anthropogenic site disappeared within one year, the animals released at the natural site thrived, and eventually spread to neighbouring habitats. Rates of reproduction at the natural site actually exceeded that of the source, and Williams et al. (1993) suggest that this may have been due to a rich, undepleted source of seed forage in the sandy soils at the previously unoccupied release site. Similar responses might occur for translocated animals in Alberta, underscoring the need to target unoccupied natural habitats as potential release sites.

Priority should also be given to unoccupied sites to avoid intraspecific competition between resident and translocated animals. For example, Goldingay et al. (1997) reports that translocating the Tipton kangaroo rat (Dipodomys nitratoides nitratoides) to occupied habitats had detrimental effects on the relocated animals due to territorial disputes with existing residents. However, sites that appear to be under-utilized by kangaroo rats (i.e. have low kangaroo rat density) may also be considered as a secondary priority for release sites because intraspecific competition at these sites is expected to be low.

Currently, most natural habitat sites in Alberta are occupied, although there are a few sites that might be unoccupied (e.g., active and semi-stable dunes in the northwest portion of the Amiens dunefield). Over-winter mortality at natural sites is variable, even for apparently high quality sites, and there have been a number of near or complete extirpations at individual sites since 1994 in the long-term monitoring records. These sites should also be considered as candidate release sites for translocations, although they could only be identified by early season (i.e. April to early May) surveys. 
A number of potential release sites were created by sand dune habitat restoration trials initiated in CFB Suffield in 2007 - 2009 (D. Bender, unpublished data). Sixteen dunes that received prescribed burn or prescribed burn/intensified grazing treatments have demonstrated their effectiveness in creating suitable habitat for kangaroo rats, as shown by the occupation by kangaroo rats following the fire treatment. While it is expected that at least some of these sites may become occupied by natural immigration over time, translocating animals to these sites would accelerate the process. One advantage of using these recently restored sites is that they may contain rich seed banks that would provide high quantity of forage to colonizing kangaroo rats.

Additional support for using recently restored sand dune habitats as suitable release sites comes from various studies that describe how kangaroo rat populations responded favourably to similar habitat enhancements elsewhere. Williams and Germano (1992) report that a moderate level of grazing was associated with a population increase of the Tipton kangaroo rat and giant kangaroo rat in California. Price et al. (1995), O'Farrell (1997), and The Nature Conservancy (1996) have all found a positive short-term response by Stephens' kangaroo rat populations to prescribed burns, with longer term improvements contingent upon continued adaptive management. Uptain et al. (1999) report on a study of four Tipton kangaroo rat populations that all underwent rapid decline, except for the single population that received fire and grazing treatments (it resisted decline and eventually appeared to stabilize in numbers). Later, fire and grazing restoration treatments were applied at one of the sites that experienced declines, which apparently stimulated a brief rebound in numbers of kangaroo rats. Similar restoration success, including successful translocations to recolonize restored habitats, has also been reported recently for the Stephens' kangaroo rat (Dipodomys stephensi) in southern California (Shier 2009).

A large wildfire occurred in May 2009 that burned about one-third of the Amiens dunefield, and it is anticipated that it has improved habitat conditions and stimulated erosion at a number of sand dunes similarly to the restoration treatments. Potential release sites may be selected (based on field reconnaissance) from these recently burned dunes, if needed. However, because no pre-existing study of these sites has been completed, great care and attention will need to be applied to choose adequate sites. To guide the selection of appropriate sites, only those recently burned sand dunes that share habitat characteristics with the successfully restored sand dunes (from the Bender et al. 2007 - 2009 habitat restoration treatments) should be considered. The main characteristics of selection would be proportion of bare soil, standing (live or dead) shrub cover, height of dune and wind fetch (exposure to prevailing winds), and proximity to nearby suitable habitat. 


\subsection{DESIGN CONSIDERATIONS FOR HANDLING AND RELEASE}

\subsection{Animal Capture and Handling}

Animal capture and handling procedures specific to the Ord's kangaroo rat in Alberta are provided in detail in Alberta Species at Risk Report No. 113 (Bender et al. 2007). In brief, kangaroo rats are located at night by flashlight or spotlight and captured by hand. Although mechanical live trapping is the most common method used in kangaroo rat studies elsewhere, hand capture has proven more effective and less prone to injure or kill kangaroo rats in Alberta (Gummer 1997b, Gummer and Robertson 2003). Captured animals are uniquely identified with a passive integrated transponder (PIT) microchip and/or eartag. The animals are held in a cloth catch bag when not being examined (for example, while preparing the microchip syringe) which helps to keep them calm and prevents injury.

Transporting a kangaroo rat from one site to another will necessitate constraining the individual for an extended period (up to a few hours). Keeping the animal in a cloth catch bag during the trip between sites is not recommended. Although relatively calm inside the bag, kangaroo rats occasionally jump around, which could lead to injury if the bag is not properly restrained. Additionally, the soft bag offers no protection against rolling or falling objects inside a moving vehicle. To increase the animal's wellbeing during transportation, holding cages should be used during transport (Emmerson and O'Farrell 1993). The use of small mammal terraria, available from most pet stores, is an inexpensive and suitable option for briefly housing kangaroo rats, provided they contain a hiding place with bedding (e.g., paper towel would be appropriate). The length of time constrained will be documented for each translocated kangaroo rat to determine if it was associated with translocation success.

Stress and risk of injury to the animal can also be reduced by minimizing the duration of captivity. This could be accomplished by moving each animal to a release site on the same night as its capture and by choosing release sites that are near to collection sites so that travel time is minimized. This limits the number of kangaroo rats that may be moved during the season, since nights in spring are short and a significant portion of each night would be spent driving from capture sites to release sites. If same night release does not prove feasible, longer-term captivity may be required. Encouragingly, most successful kangaroo rat translocation studies have used this method. For example, O'Farrell (1999) captured San Bernardino kangaroo rats (Dipodomys merriami parvus) for four nights before releasing them all on the fifth night. Care must be taken to provide the animals with comfortable environments for longer term captivity. Emmerson and O'Farrell (1993) reports that kangaroo rats handle captivity well under proper conditions: housed individually in a sturdy terrarium with ventilation, a quiet hiding space partially filled with paper towel for bedding, food, individual housing, and even water (although kangaroo rats can survive on metabolized water, animals may drink when stressed even if they normally do not do so in the wild). Williams et al. (1993) approximated the amount of food to be used as 1/10 the animal's body weight in seed per day. They had success with a seed mixture of $75 \%$ proso white millet and $25 \%$ oats groats for the giant kangaroo rat. In addition, Gummer (2005) temporarily held Ord's 
kangaroo rats successfully in Alberta for up to 24 hours in small cages with clean sand, cardboard nest box, and native grass seed harvested by hand in the study area.

Kangaroo rats are particularly sensitive to low frequency sound: noises such as a furnace fans appeared to cause unnecessary aggravation and stressful behaviours in kangaroo rats during temporary captivity (Gummer unpublished data) and therefore such auditory disturbances should be minimized.

Contingency plans for holding animals longer than anticipated must also be developed. Unforeseen problems often arise during the course of field work, and delays in relocation efforts are not uncommon in kangaroo rat translocation experiments. O'Farrell (1993) experienced delays when required to remove Stephens' kangaroo rats from an area facing habitat disruption before the release sites were available. More recent work on this species was delayed for months due to an extreme heat spell (Shier 2009). Although less dramatic, even a flat tire could be enough to force the holding of individuals longer than planned. Thus, even if same-night translocations are planned, daytime holding facilities using containers and methods described above must be available in the case that unforeseen events prevent timely release of captured animals.

\subsection{Soft Release Methods}

Despite some disagreement in the literature, many kangaroo rat translocation studies have used and recommend using soft release methods for improving chances of animal establishment at release sites. Shier and Swaisgood (2006) describe post-release dispersal from release sites and mortality as the two primary reasons for failure in translocation attempts with heteromyids, both of which can be caused by the stress of an unfamiliar environment (Davis and Stamps 2004, Shier 2007). Montgomery (1997) found mortality to be highest within the first few days of translocating Stephens' kangaroo rats. As opposed to a hard release in which the animal is released immediately into its new surroundings, a soft release provides food, shelter, and sometimes, temporary constraint to prevent an animal from escaping the release site until it has acclimatized to its new surroundings.

Soft release requires release of the animal to an acclimation area. For kangaroo rats, the best way to accomplish this is to construct an artificial underground nest chamber with burrows connecting to the surface. Williams et al. (1993) used corrugated cardboard for the chamber frame and cardboard tubes for burrows. The nest chamber was partially filled with paper towels for bedding. The flimsy nature of cardboard resulted in some collapsing of burrows, and although easily replaced, this increased the workload. Shier (2009) has been using chicken wire cages for the nest chamber along with plastic tubing (corrugated to provide traction) for the burrows. Given the highly aggressive, territorial nature of kangaroo rats, both studies introduced only a single kangaroo rat per chamber.

Two release methods have been advocated, differing mostly on the timing of the animal's release. The common method appears to be a night-time release where animals are transported and released under the cover of dark. In some instances (e.g., Shier, 2009), animals have been released into a chicken wire enclosure to temporarily 
prevent them from escaping the release site. While establishment rates are generally reported to be higher in the literature when enclosures are used, there is an apparent bias because the fate of animals who disappear from non-enclosed released sites is typically unknown (i.e. they may have established themselves nearby, but it was not observed). A different release mechanism was used by Williams et al. (1993) whereby they actually released their kangaroo rats after sunrise. At the release site, kangaroo rats were deposited into artificially constructed burrow tubes, which were then sealed at the surface with paper towels and soil. The burrows were then monitored closely to ensure the animals did not emerge during daylight hours (if they did attempt to escape, they were recaptured and placed back in the burrow tube). The tubes were then unplugged during the evening so the kangaroo rats could leave the burrow, and hopefully, establish themselves in their new surroundings.

Successful hard release methods have also been reported. O'Farrell's (1999) study on translocating the San Bernardino kangaroo rat demonstrated that soft releases are always necessary for successful establishment of translocated rats. O'Farrell also summarizes some of the key factors that appear to be related to successful establishment:

- releasing kangaroo rats into suitable unoccupied habitat that is surrounded by a hostile matrix of unsuitable habitat;

- presence of other rodent burrows and shrub cover; and

- releasing animals as soon as it is dark, thus allowing the greatest length of time for the kangaroo rat to settle into its new surroundings on the first night.

The last point is probably most important if hard releases are to be attempted, but may be helpful in soft releases as well. Providing more night time makes it more likely that a burrow will be prepared. However, the benefits of an early release are likely offset by the need to store an animal in captivity during the daytime, which may increase its level of stress and disorientation. More research is needed regarding hard vs. soft release techniques before it will be possible to suggest the optimal approach.

Another consideration for releasing translocated animals is the provision of a food supply. While the provision of food is a relatively common practice, it is not clear from the literature if this is necessarily beneficial. Williams et al. (1993) provided a food supply to help the animals establish their new territory. They placed an initial cache of $2.3 \mathrm{~kg}$ of seeds in the nest chamber ( $75 \%$ proso white millet and $25 \%$ oats groats). Additional seed was later provided for an estimated year's food supply, with the first supplement of $1 \mathrm{~kg}$ supplied approximately three weeks after release. In the case of using chicken wire enclosures, providing seed is a definite requirement since the animals are not free to forage for food. Without the use of soft release enclosures, the provision of appropriate forage is likely beneficial and should be attempted.

One study has also suggested that predator deterrence may help improve the success of survival following translocation. Shier (2009) has experimented with mountain lion urine as a predator deterrent: using 50 kangaroo rat release sites, half were treated with the urine while the other half were control sites treated with ordinary water. The results of this study are not yet available, but it was observed by the researcher that some of 
the kangaroo rats have taken to digging burrows next to the urine patches. This may indicate that deterrent does not seem to bother kangaroo rats, at least. Such treatments might be attempted in Alberta translocations, but only if predation becomes problematic at release sites. Other predator urine, such as coyote urine, might be more applicable at Alberta sites.

\subsection{POST-RELEASE INVESTIGATIONS AND MONITORING}

Post-release monitoring and investigation is a critical step for any translocation program, regardless of whether the purpose is to research the effectiveness of a particular technique or the translocations are used purely as a conservation tool. Obviously, in either case the outcome of the translocation (i.e. whether or not the individual established a new residence and survived) is important to understand.

Both research studies and conservation tools have an opportunity to monitor kangaroo rats after release (typically from one month to one year's time) and collect information regarding the outcome of the translocation. For research purposes, the outcome may be statistically related to factors manipulated in the release (e.g., hard vs. soft techniques used) or site specific factors (e.g., type and degree of cover of vegetation at release site) to determine what methods were most or least successful. If translocations are employed purely as a conservation tool, habitat characterization and post-release monitoring at capture and release sites are recommended to document whether the treatments had the desired effect, whether the benefits of translocation successes outweigh their costs, and to provide adaptive feedback to improve future efforts.

\subsection{Post-release Monitoring}

In the literature, the frequency and timing of post-release monitoring varies among studies, depending on the objectives of the studies and schedules and funding of the researchers. In Alberta, the season of above-ground activity (particularly breeding) is relatively short, with most above-ground activity limited to the months between April and October, inclusive. Bi-weekly or monthly monitoring of kangaroo rat release sites is quite feasible over this time period. Further, remote monitoring using infrared cameras or video systems may greatly extend our capability to monitor the presence and activities of kangaroo rats at release sites. Such systems can be deployed prior to release and record near continuous records of kangaroo rat activity following release. A combination of remote monitoring and regular site visits by researchers would likely yield the most useful information.

One monitoring technique that has been used on kangaroo rats is radio telemetry. For example, Gummer and Robertson (2003) successfully used radio telemetry in Alberta to monitor the activity and body temperatures of kangaroo rats in their underground burrows. While this method may be useful for monitoring established kangaroo rats after a successful translocation, it would be more difficult to monitor the fate of 
translocated individuals immediately upon release, (i.e., if they leave the release site). Radio transmitters that are small enough to be attached to kangaroo rats (see Gummer and Robertson 2003) are readily available but emit a relatively weak radio signal that is largely attenuated by soil, particularly if the animal is underground at the depth of a burrow (estimated to be between 100 and $150 \mathrm{~cm}$ ). Thus, if a kangaroo rat leaves a release site and travels any great distance, the chance of searching and finding it (particularly during the daytime when it is below ground) is expected to be low. It would be necessary to conduct extensive searches in surrounding habitats during nighttime periods when kangaroo rats would be expected to be aboveground and the radio signal could be detected at larger distances (e.g., 1-2 km). The effort required to successfully use this method may be justified if it is necessary to determine the specific fates of translocated individuals.

\subsection{Habitat Characterization}

Each release site will have been chosen (see Section 3.4 above) to reflect high quality habitat and maximize the potential of survival for translocated kangaroo rats. As part of this process, certain habitat characteristics should be assessedto facilitate post-release investigations to understand the factors that lead to successful patterns of establishment and survival. The types of habitat characteristics that should be assessed to feed into a post-release investigation would include information about:

- vegetation cover/bare soil cover

- plant composition

- amount of dead organic material accumulated on soil surface

- soil characters (texture, composition)

- type of habitat (e.g., sand dune, eroding slope, road)

- availability of other rodent burrows (e.g., pocket gophers, ground squirrels)

- slope and slope position of release site

- aspect of release site

- elevation of release site relative to local area

- presence of active erosion at release site

- distance to roads, trails, or other anthropogenic linear features

- distance to nearest open sand habitat and nearest known kangaroo rat location

- distance to nearest trees or buildings as perch sites for predators

- time since last fire (if known)

- site disposition (e.g., low-intensity livestock grazing, high-intensity grazing, no grazing, cultivated field, maintained road, unmaintained trail, etc.)

\subsection{Post-release investigation}

Post-release investigations integrate information about translocation success (e.g., establishment status, or survival) and other factors that may be related to these 
measures of success (e.g., habitat characters, timing of release, weather conditions at time of release, age/sex/reproductive category of released animals, etc.). When such information is available, it is always recommended that post-release investigation be undertaken to diagnose the factors associated with successful releases (or lack thereof).

Standard techniques for relating patterns of establishment/non-establishment (e.g. logistic regression; see Hosmer and Lemeshow 2000) or survival analysis (e.g., Cox proportional hazards models; see Cox and Oakes 1984, Therneau and Grambsch 2000) can be employed. Such techniques allow one to investigate whether patterns of establishment or survival can be explained by intrinsic or extrinsic factors in the study. Typically, such methods are best used when strong a priori experimental design is undertaken, so it is recommended that these studies are designed prior to translocations rather than ad hoc statistical analysis.

\subsection{CONCLUSIONS AND RESEARCH RECOMMENDATIONS}

The question of whether or not translocations of animals can be used to successfully manage Ord's kangaroo rats in Alberta is currently a difficult one to answer. While there have been some successes reported in the literature for other species of kangaroo rats (e.g., O'Farrell 1999; Shier 2009), mixed success or low success is also reported (e.g., Uptain et al. 1999, LSA Associates Inc. 2002). It is difficult to predict how Ord's kangaroo rats, particularly those in Alberta that are stressed further by the extremes of our northerly climate, will respond.

While this report attempts to summarize 'best practices' for conducting translocations of Ord's kangaroo rats, a major conclusion of this report is that research is needed in a number of specific areas before translocations should be considered for use as a conservation and management tool. Research items include:

1. Do hard or soft release techniques provide the best chance of establishment by kangaroo rats at release sites? Both techniques appear to be at least partly successful based on previous studies, but each is suited to different conditions. For example, soft releases apparently facilitate establishment of residences, especially if animals are prone to fleeing immediately upon release. Daytime releases into an artificial burrow may alleviate the need for enclosures, but animals may be prone to fleeing as soon as night returns. More research is required to learn whether Ord's kangaroo rats in Alberta respond best to hard or soft releases. Until such research is completed, there is no reason to expect that one is necessarily better than the other and both techniques should be investigated.

2. What is the optimal timing for translocations? Spring and early-summer translocations during the darkest periods of the lunar calendar seem obvious for this species, but past studies disagree about what time of day/night is best for release. Since there have been mixed successes with both daytime and night- 
time releases, this factor could be investigated. Night-time releases appear to be most useful if kangaroo rats in Alberta are not prone to immediately moving away from their release sites, or if soft release enclosures are used. Daytime releases may eliminate the need for release enclosures, but animals might simply flee the area at first nightfall regardless. Detailed post-release monitoring using both human observers, remote cameras, and possibly radio telemetry could provide very useful information here.

3. Is it better to translocate adults or juveniles? There is a rich source of juveniles primed to disperse each spring, making this an attractive group to collect for translocations since they are not likely to remain in their natal territory anyways. However, translocating adults may have great benefits, particularly since they are reproductively mature at the time of the translocation and have previous experience establishing a residence, territory, and seed cache. Research about the long-term success (i.e. persistence $>1$ year, reproductive success) of translocated animals is required, as well as information about establishment and short-term (i.e., summer) survival. Long-term mark-recapture studies designed for population monitoring may be the most cost-effective means to study these effects. It is recommended that all translocation sites be integrated into the Alberta long-term population monitoring program (see Bender et al. 2007).

4. What habitat characters best promote successful translocations? Perhaps the greatest gap in our knowledge is what habitat features are selected by dispersing kangaroo rats. Therefore, it is difficult to predict how translocated animals will respond to the move to a new habitat. A range of habitat characters that seem probable for supporting kangaroo rats, based on previously observed occurrences, could be examined in a translocation experiment. For example, release sites with sandy soils of varying vegetation cover from light to very sparse to negligible could become targets for translocated animals. If sufficient replication were available, one could examine statistically whether a pattern of success emerged with respect to degree of vegetation cover. Similarly, if release site characters were recorded and post-release monitoring was conducted as part of a longer-term management program to relocate kangaroo rats (e.g., to mitigate extirpation of isolated populations), there may be additional opportunity to perform statistical analysis on these opportunistic data and further test factors influencing translocation success. Thus, careful note-taking and data management regarding site assessments and post-release monitoring must be maintained. This would be facilitated if standardized methods for assessing habitat characteristics, etc. were established.

Opportunities for conducting research on translocating kangaroo rats in Alberta may paradoxically be linked to the animal's fate. If loss of habitat or population declines were to accelerate, wildlife managers may be compelled to use a conservation tool like translocations to manage and recover the population. However, this might be the most risky time to attempt a translocation study because the population would be at its highest risk of extinction and the fate of only a few individuals might be enough to tip the balance between persistence and extirpation. Instead, the best time to conduct such research is when the population is as stable and secure as possible, 
although the urgency of such research may be lower. It is recommended that research about best practices for Ord's kangaroo rat translocations in Alberta be undertaken while the population size and site occupancy are relatively high in the province. 


\subsection{LITERATURE CITED}

Alberta Ord's Kangaroo Rat Recovery Team. 2005. Recovery plan for Ord's kangaroo rat in Alberta. Alberta Sustainable Resource Development, Fish and Wildlife Division, Alberta Species at Risk Recovery Plan No. 5. Edmonton, AB. 28 pp.

Bender, D.J., D.L. Gummer, and R. Dzenkiw. 2007. Monitoring protocol for the Ord's kangaroo rat in Alberta. Alberta Sustainable Resource Development, Fish and Wildlife Division. Alberta Species at Risk Report No. 113, Edmonton, AB. 21 pp.

COSEWIC. 2006. COSEWIC assessment and update status report on the Ord's kangaroo rat, Dipodomys ordii in Canada. Committee on the Status of Endangered Wildlife in Canada. Ottawa, ON. vii +34 pp.

Cox, D.R. and D. Oakes 1984. Analysis of survival data. Chapman \& Hall, London, UK.

Gliwicz, J. 1991. Patterns of dispersal in non-cyclic populations of small rodents. In: Animal Dispersal: Small Mammals as a Model. Stenseth and W.Z. Lidiceker, Eds. University of Chicago Press, Chicago, IL. N.C., 384 pp.

Gummer 1997a. Effects of latitude and long-term isolation on the ecology of northern Ord's kangaroo rats (Dipodomys ordii). M.Sc. thesis, Department of Biological Sciences, Univ. of Calgary, Calgary, Alberta. $111 \mathrm{pp}$.

Gummer, D.L. 1997b. Ord's kangaroo rat (Dipodomys ordii). Alberta Environment Management Division, Wildlife Status Report No. 4, Edmonton, AB. 16pp.

Gummer, D.L., M.R. Forbes, D.J. Bender, and R.M.R. Barclay. 1997. Botfly (Diptera: Oestridae) parasitism of kangaroo rats (Dipodomys ordii) at Suffield National Wildlife Area, Alberta, Canada. Journal of Parasitology 83:601-604.

Gummer, D.L. 2005. Geographic variation in torpor patterns: The northernmost prairie dogs and kangaroo rats. Ph.D. thesis, Univ. of Saskatchewan. Saskatoon, SK. $210 \mathrm{pp}$.

Gummer, D.L., M.R. Forbes, D.J. Bender, and R.M.R. Barclay. 1997. Botfly (Diptera: Oestridae) parasitism of kangaroo rats (Dipodomys ordii) at Suffield National Wildlife Area, Alberta, Canada. Journal of Parasitology 83:601-604.

Gummer, D.L. and S.E. Robertson. 2003. Distribution of Ord's Kangaroo Rats in Southeastern Alberta. Alberta Sustainable Resource Development, Fish and Wildlife Division, Alberta Species at Risk Report No. 63. Edmonton, AB. 16 pp.

Hosmer, D.W. and S. Lemesow. 2000. Applied Logistic Regression, $2^{\text {nd }}$ ed. John Wiley and Sons, New York, NY. 375 pp. 
Kissner, K.J. 2009. Beneficial management practices for Ord's kangaroo rats in Alberta. Alberta Sustainable Resource Development, Fish and Wildlife Division, Alberta Species at Risk Report No. 125. Edmonton, AB. 42 pp.

Teucher, A.C. 2007. Impacts of anthropogenic habitat use on the Ord's kangaroo rat (Dipodomys ordii) in Alberta. M.Sc. thesis, Department of Biological Sciences, Univ. of Calgary. Calgary, AB. 167 pp.

Therneau, T.M. and P.M. Grambsch. 2000. Modeling survival data: extending the Cox Model. Springer-Verlag, Berlin, Germany. 350 pp. 
For a list of additional reports in the Alberta Fish and Wildlife Division - Species at Risk Series please go to our website:

http:www.srd.alberta.ca/BiodiversityStewardship/SpeciesAtRisk/ProgramReports.aspx 


